\title{
CARACTERIZAÇÃO MORFOLÓGICA EM PASTOS DE CAPIM- MARANDU SUBMETIDOS A FREQUÊNCIAS DE DESFOLHAÇÃO E NÍVEIS DE ADUBAÇÃO
}

\section{MORFOLOGIC CHARACTERIZATION ON MARANDU GRASS PASTURES SUBMITTED TO DEFOLIATION FREQUENCIES AND FERTILIZATION LEVELS}

\author{
Jéssica Abreu de Sá Medica ${ }^{*}$ \\ Natani Silva Reis ${ }^{1}$ \\ Manoel Eduardo Rozalino Santos ${ }^{1}$ \\ 1 Universidade Federal de Uberlândia, Uberlândia, MG, Brasil. \\ *Autora para correspondência - jessicah.abreu@hotmail.com
}

\section{Resumo}

Os perfilhos são as unidades básicas de crescimento das gramíneas forrageiras e o perfilhamento é responsável pela adaptação e reestabelecimento da gramínea após a desfolhação. Portanto, é importante conhecer as modificações morfológicas dos perfilhos em função do ambiente de desfolhação e da adubação, duas importantes estratégias de manejo das pastagens. Assim, objetivou-se com este trabalho caracterizar as respostas morfológicas dos perfilhos do capimmarandu, em resposta à adubação e à frequência de desfolhação, para melhor compreensão da plasticidade fenotípica dessa planta. $\mathrm{O}$ trabalho foi realizado em dois anos experimentais, em que foram avaliados distintos intervalos de corte (sete, 14, 28, 56 e 112 dias), utilizando-se o delineamento em blocos casualizados, com quatro repetições. No segundo ano, além dos mesmos intervalos de corte avaliados no primeiro ano, também foram estudadas duas condições de adubação, sendo uma baixa (21,5 kg.ha ${ }^{-1}$ de P e 75 kg.ha- ${ }^{-1}$ de $\left.\mathrm{N}\right)$ e outra alta (43 kg.ha-1 de P e 300 $\mathrm{kg} . \mathrm{ha}^{-1}$ de N). No segundo ano, utilizou-se o esquema fatorial. Em ambos os anos, as respostas para comprimento de colmo, comprimento da lâmina foliar, espaço entre as lâminas foliares e área foliar e peso do perfilho foram crescentes com o intervalo de corte. No segundo ano, a alta dose de adubos proporcionou maior número de perfilhos vegetativos, espaço entre lâminas foliares, área foliar, peso de perfilhos, folhas e colmos mais compridos, em comparação à baixa dose de adubos. No segundo ano, houve maior densidade populacional de perfilho reprodutivo com o maior intervalo de corte. A desfolhação e a adubação nitrogenada e fosfatada causam modificações morfológicas nos perfilhos do capim-marandu, indicando a ampla plasticidade fenotípica desta gramínea.

Palavras-chave: fósforo; intervalo de corte; nitrogênio; Urochloa brizantha.

\begin{abstract}
Tillers are the basic units of growth in forage grasses and tillering is responsible for the adaptation and reestablishment of grass after defoliation. Therefore, it is important to understand the morphological changes of tillers due to defoliation environment and fertilization, which are two important pasture management strategies. In this study, we aimed to characterize the morfologic
\end{abstract}


response of marandu grass tillers before nitrogen fertilization and frequency of defoliation for a better understanding of the phenotypic plasticity of this plant. This study was carried out in two experimental years. The treatments in the first year consisted of different cutting intervals $(7,14$, 28, 56, and 112 days). In the second year, besides the same cutting intervals, two fertilization conditions were studied: a low level $\left(21.5 \mathrm{~kg} \cdot \mathrm{ha}^{-1} \mathrm{P}\right.$ and $\left.75 \mathrm{~kg} \cdot \mathrm{ha}^{-1} \mathrm{~N}\right)$ and a high level $\left(43 \mathrm{~kg} \cdot \mathrm{ha}^{-1} \mathrm{P}\right.$ and $300 \mathrm{~kg} \cdot \mathrm{ha}^{-1} \mathrm{~N}$ ). A randomized block design was adopted and in experiment two a factorial scheme with four repetitions was used. In both experiments the responses to stem length, leaf blade length, space between leaf blade and leaf area, and weight of tiller increased with cutting intervals. In experiment two, high doses of fertilization provided larger number of vegetative tillers, space between leaf blades, tiller weight, longer leaves and stems, and higher population densities of reproductive tillers with longer cutting intervals. In conclusion, the defoliation and the nitrogen and phosphorous fertilization produced morphologic modifications in marandu grass tillers suggesting the phenotypic plasticity of this grass.

Keywords: cutting interval; nitrogen; phosphorous; Urochloa brizantha.

Recebido em: 28 março 2016

Aceito em: 17 outubro 2016

\section{Introdução}

O capim-marandu adapta-se à precipitação pluvial anual ao redor de $700 \mathrm{~mm}$ e cerca de cinco meses de seca no inverno. Ele não suporta solos encharcados e é recomendado para áreas de média a boa fertilidade de solo, embora tolere acidez no solo ${ }^{(1)}$. Quando adequadamente manejado, o capim-marandu apresenta alta resposta à adubação e elevado potencial de produção de forragem, de até $36 \mathrm{t} /$ ha.ano de $\mathrm{MS}^{(2)}$. Devido às suas características, no Brasil, existem 60 milhões de hectares de pastagens formadas com Urochloa brizantha cv. Marandu (capim-marandu), o que representa $65 \%$ da área de pastagem cultivada na região Norte e $50 \%$ na região Centro-Oeste ${ }^{(3)}$.

O pasto é formado por uma população de perfilhos ${ }^{(4)}$, considerados unidades básicas de crescimento das gramíneas e constituídos de uma série de fitômeros (lâmina foliar, bainha, lígula, nó, entrenó e gema axilar), os quais se diferenciam a partir de um único meristema ${ }^{(5)}$. Com o pastejo ou o corte, a gramínea forrageira modifica a morfologia de seus perfilhos. Nesse sentido, sob desfolhação severa, os perfilhos passam a ser menores, mais leves e com órgãos (folhas e colmo) mais curtos ${ }^{(6)}$. Com essas modificações morfológicas, as lâminas foliares podem continuar se desenvolvendo e realizar fotossíntese, sem que sejam acentuadamente removidas pelo animal em pastejo. Desse modo, o perfilhamento e a caracterização morfológica dos perfilhos individuais são essenciais para compreender os fatores que interferem na produção de forragem e na estrutura do dossel forrageiro $^{(7)}$.

A adubação, como a nitrogenada e a fosfatada, aumenta o crescimento dos perfilhos, bem como o seu número, quando o pasto é mantido baixo ${ }^{(6)}$. Na presença do nitrogênio, ocorre maior taxa de aparecimento foliar ${ }^{(8)}$ e, com efeito, maior número de gemas axilares será produzida, podendo originar novos perfilhos, caso a quantidade e a qualidade da luz incidente sobre as mesmas sejam satisfatórias. Esses fatores fazem com que o pasto aumente sua produção de forragem e alcance mais rapidamente a condição adequada de desfolhação.

Diante do exposto, as modificações na frequência de desfolhação e na disponibilidade de nutrientes 
no solo geram respostas adaptativas nas plantas forrageiras que ocorrem por meio de modificações no seu desenvolvimento, alterando sua morfologia. Dessa forma, objetivou-se neste trabalho descrever algumas alterações morfológicas dos perfilhos do capim-marandu sob diferentes níveis de adubação e frequências de desfolhação, para melhor compreensão da plasticidade fenotípica dessa importante gramínea forrageira.

\section{Material e Métodos}

Este trabalho foi conduzido em dois períodos: de outubro de 2013 até fevereiro de 2014 e de novembro de 2014 até março de 2015. Em cada período, experimentos independentes porém com natureza semelhante foram realizados. Os dois experimentos, denominados de Experimento 1 e Experimento 2, ocorreram em áreas experimentais distintas de $100 \mathrm{~m}^{2}$ cada, porém na mesma pastagem, que foi estabelecida no ano de 2000 com Urochloa brizantha Stapf. cv. Marandu (capimmarandu). A pastagem localizava-se na Fazenda Experimental Capim-branco, pertencente à Universidade Federal de Uberlândia, em Uberlândia, Minas Gerais. As coordenadas geográficas do local do experimento são $18^{\circ} 30^{\prime}$ de latitude sul e $47^{\circ} 50^{\prime}$ de longitude oeste de Greenwich com altitude de $863 \mathrm{~m}$. O clima da região é tropical de altitude, com inverno ameno e seco e estação seca e chuvosa bem definida. A temperatura e precipitação média anual são de $22,3{ }^{\circ} \mathrm{C}$ e $1584 \mathrm{~mm}$, respectivamente. As informações referentes às condições climáticas durante o período experimental foram monitoradas na estação meteorológica localizada aproximadamente a $200 \mathrm{~m}$ da área experimental (Tabela 1).

Tabela 1. Médias mensais de temperaturas diárias, radiação solar, precipitação e evapotranspiração durante o período de outubro de 2013 a fevereiro de 2014 e de novembro de 2014 a março de 2015

\begin{tabular}{|c|c|c|c|c|c|c|}
\hline \multirow[t]{2}{*}{ Mês } & \multicolumn{3}{|c|}{$\begin{array}{c}\text { Temperatura média do ar } \\
\left({ }^{\circ} \mathrm{C}\right)\end{array}$} & \multirow{2}{*}{$\begin{array}{c}\text { Radiação } \\
\text { solar } \\
\text { (Mj/mês) }\end{array}$} & \multirow{2}{*}{$\begin{array}{c}\text { Precipitação } \\
\text { pluvial } \\
\text { (mm/mês) }\end{array}$} & \multirow{2}{*}{$\begin{array}{c}\text { Evapotranspiração } \\
\text { (mm/mês) }\end{array}$} \\
\hline & Média & Mínima & Máxima & & & \\
\hline & \multicolumn{6}{|c|}{ Experimento $1(2013-2014)$} \\
\hline Out & 23,5 & 18,4 & 29,8 & 608,9 & 81,6 & 104,1 \\
\hline Nov & 23,5 & 19,1 & 29,0 & 576,3 & 91,0 & 95,1 \\
\hline Dez & 23,1 & 19,5 & 28,8 & 566,9 & 229,4 & 90,7 \\
\hline Jan & 23,9 & 18,4 & 30,5 & 696,3 & 58,4 & 115,0 \\
\hline \multirow[t]{2}{*}{ Fev } & 23,8 & 18,5 & 30,2 & 550,9 & 75,2 & 92,6 \\
\hline & \multicolumn{6}{|c|}{ Experimento 2 (2014-2015) } \\
\hline Nov & 23,6 & 17,1 & 32,6 & 548,8 & 347,2 & 89,2 \\
\hline Dez & 22,7 & 17,0 & 32,1 & 545,8 & 210,8 & 87,1 \\
\hline Jan & 25,4 & 18,3 & 33,3 & 591,6 & 121,0 & 101,0 \\
\hline Fev & 23,0 & 17,2 & 32,8 & 549,6 & 166,6 & 88,5 \\
\hline $\begin{array}{l}\text { Mar } \\
\text { Mar }\end{array}$ & 21,8 & 18,3 & 27,9 & 522,0 & 78,4 & 81,4 \\
\hline
\end{tabular}


O solo da área experimental é classificado como Latossolo Vermelho Escuro Distrófico, com textura argilosa ${ }^{(9)}$. Antes da implantação dos experimentos foram retiradas amostras de solo na camada 0-10 cm para análise do nível de fertilidade. No Experimento 1, os resultados foram: $\mathrm{pH}$ em $\mathrm{H}_{2} \mathrm{O}=5,5 ; \mathrm{P}=1,3$ (Mehlich-1); $\mathrm{K}=75 \mathrm{mg} \mathrm{dm}{ }^{-3} ; \mathrm{Ca}^{2+}=1,7 ; \mathrm{Mg}^{2+}=1,1 \mathrm{e} \mathrm{Al}^{3+}=0,0 \mathrm{cmol}_{\mathrm{c}} / \mathrm{dm}^{3}$ ( $\mathrm{KCl} 1$ mol. $\mathrm{L}^{-1}$ ). No Experimento 2, os resultados foram: $\mathrm{pH}$ em $\mathrm{H}_{2} \mathrm{O}=6,0 ; \mathrm{P}=5,2$ (Mehlich-1); $\mathrm{K}$ $=156 \mathrm{mg} \mathrm{dm}{ }^{-3} ; \mathrm{Ca}^{2+}=5,4 ; \mathrm{Mg}^{2+}=2,0 \mathrm{e} \mathrm{Al}^{3+}=0,0 \mathrm{cmol}_{\mathrm{c}} \mathrm{dm}^{-3}\left(\mathrm{KCl} 1 \mathrm{~mol} . \mathrm{L}^{-1}\right)$. Com base nesses resultados e de acordo com as recomendações de Cantarutti et al. ${ }^{(10)}$ para uma pastagem sob médio nível tecnológico, não foi necessário efetuar a calagem e nem a adubação potássica.

No Experimento 1, as adubações fosfatada e nitrogenada foram realizadas após corte de uniformização do dossel forrageiro a $5 \mathrm{~cm}$ de altura, em 15 de novembro de 2013, com a aplicação de $70 \mathrm{~kg} \cdot \mathrm{ha}^{-1}$ de $\mathrm{N}$ e 21,5 kg.ha- ${ }^{-1}$ de P, utilizando como fontes a ureia e o superfosfato simples. As adubações foram realizadas com única aplicação ao fim da tarde e em cobertura.

Nos dois experimentos, foram avaliados cinco intervalos de cortes (7, 14, 28, 56 e 112 dias), que caracterizaram as distintas frequências de desfolhação a que o capim-marandu foi submetido. Como o período de avaliação foi de 112 dias, o número de eventos de desfolhação foi variável durante o período experimental, de modo que ocorreram 16, oito, quatro, duas e uma desfolhações para os intervalos de cortes de 7, 14, 28, 56 e 112 dias, respectivamente. Cada intervalo de corte foi implementado em quatro unidades experimentais. No segundo período experimental (Experimento 2), além dos intervalos de cortes, também foram avaliadas duas condições de adubação (baixa e alta). A condição de baixa adubação correspondeu à aplicação de 21,5 kg.ha-1 de $\mathrm{P}$ e de $75 \mathrm{~kg} \cdot \mathrm{ha}^{-1}$ de $\mathrm{N}$ após o corte de uniformização do dossel forrageiro em $10 \mathrm{~cm}$ no dia 10/11/2014. A condição de alta adubação correspondeu à aplicação de $43 \mathrm{~kg} \cdot \mathrm{ha}^{-1}$ de $\mathrm{P}$ e $300 \mathrm{~kg} \cdot \mathrm{ha}^{-1}$ de $\mathrm{N}$, em que o adubo fosfatado foi aplicado após o corte de uniformização, enquanto que o adubo nitrogenado foi aplicado em quatro parcelas de $75 \mathrm{~kg} \cdot \mathrm{ha}^{-1}$ de $\mathrm{N}$ nos dias 10/11/2014, 08/12/2014, 05/01/2015 e 02/02/2015. Como fontes de adubos, foram usados o superfosfato simples e a ureia.

Em ambos os experimentos, devido ao relevo levemente inclinado da área experimental, foi adotado o delineamento em blocos casualizados. Os blocos foram dispostos perpendicularmente à declividade do terreno. A unidade experimental correspondeu a uma área demarcada com 1,0 $\mathrm{m}^{2}$ que, descontando-se 0,25 $\mathrm{m}$ de bordadura, teve área útil de $0,25 \mathrm{~m}^{2}$. No Experimento 2, adotou-se o esquema fatorial, com quatro repetições. Nas datas dos cortes, removeu-se com tesoura de poda todos os componentes da parte aérea da planta que estavam acima de $5 \mathrm{~cm}$ ou de $10 \mathrm{~cm}$ da superfície do solo nos Experimentos 1 e 2, respectivamente. Após a constatação no Ano 1 de que a altura pós-corte de $5 \mathrm{~cm}$ foi muito drástica, trabalhou-se com $10 \mathrm{~cm}$ no Ano 2 . Todas as avaliações ocorreram antes do último corte de cada intervalo avaliado, isto é, em 28/02/2014 para o Experimento 1 e em 02/03/2015 para o Experimento 2.

Os números de perfilhos vegetativos e reprodutivos em cada unidade experimental foram quantificados, pela contagem das categorias de perfilhos no campo, de modo não destrutivo. $\mathrm{O}$ perfilho vivo com inflorescência visível foi classificado como reprodutivo; enquanto que aquele vivo e sem inflorescência, foi denominado de vegetativo.

A caracterização morfológica de perfilhos individuais foi realizada em dez perfilhos vegetativos no Experimento 1 e em cinco perfilhos vegetativos no Experimento 2 por unidade experimental. Nestes, foram quantificados os comprimentos do colmo e da lâmina foliar, bem como a largura da lâmina foliar e os números de folhas vivas, cortadas e mortas. O comprimento do colmo foi mensurado desde o nível do solo até a lígula da folha mais jovem completamente expandida no 
último dia do experimento. As dimensões da lâmina foliar foram medidas na folha viva localizada no nível de inserção intermediário no perfilho. O comprimento da lâmina foliar foi medido desde o ápice até a lígula da folha. A largura da lâmina foliar foi mensurada no meio deste órgão. As folhas vivas consistiram de folhas em expansão e expandidas. As folhas vivas com remoção parcial de sua lâmina foliar foram consideradas como cortadas. Apenas as folhas que possuíam mais de $50 \%$ da lâmina foliar senescente foram classificadas como mortas. Pela divisão entre o comprimento do colmo e o número de folhas vivas expandidas mais mortas, estimou-se a distância entre folhas no perfilho.

O peso do perfilho foi estimado pela divisão da massa de forragem pelo número de perfilhos vivos. A massa de forragem foi obtida pelo corte, rente ao solo, de todos os perfilhos contidos na unidade experimental. Essa amostra foi pesada e dividida em duas subamostras. Uma das subamostras também foi colocada para secar por 72 horas em estufa de ventilação forçada a $65{ }^{\circ} \mathrm{C}$ efoi pesada ao término desse período. A outra subamostra teve suas lâminas foliares separadas, pesadas, secas em estufa e pesadas novamente. Com esses dados, calculou-se a massa de lâmina foliar do capimmarandu. Pela multiplicação da massa de lâmina foliar pela área foliar específica (AFE), descrita no próximo parágrafo, obteve-se o índice de área foliar (IAF) do dossel. Por sua vez, com a divisão do IAF pelo número de perfilhos vivos, estimou-se a área foliar média do perfilho.

Para a determinação da AFE, fez-se a colheita de 40 lâminas foliares em cada parcela. Estas foram colocadas em sacos plásticos identificados e levados para o laboratório onde foi feito o corte das extremidades de cada lâmina foliar, de forma que elas ficassem em formato retangular. Posteriormente, mediu-se o comprimento e a largura de cada uma delas, a fim de se estimar a área de cada segmento de lâmina foliar. Com isso, foi possível obter a área total dos 40 segmentos de lâmina foliar. As lâminas foliares foram, então, acondicionadas em sacos de papel identificados e levadas à estufa de ventilação forçada a $65^{\circ} \mathrm{C}$ por 72 horas, sendo pesadas após esse período. Por meio desses resultados de área e peso dos segmentos foliares, foi calculada a AFE em $\mathrm{cm}^{2} \cdot \mathrm{mg}^{-1}$.

Os dados obtidos foram submetidos à análise de variância, em delineamento de blocos casualizados. No Experimento 2, no qual foram avaliados dois fatores (intervalo de corte e condição de adubação), a análise dos dados seguiu o esquema fatorial e, quando a interação entre os fatores não foi significativa, realizou-se a comparação entre as médias marginais dos níveis de cada fator. Quando a interação entre os fatores foi significativa, realizou-se a comparação dos níveis de um fator em separado para cada nível do outro fator. Todas as análises foram feitas com o teste de Tukey, admitindo-se uma probabilidade de ocorrência do erro tipo I de 5\%.

\section{Resultados}

Foram avaliadas nove características do capim-marandu. Destas, no Experimento 1, cinco foram influenciadas pelo intervalo de corte, enquanto que no Experimento 2 seis foram influenciadas pelo intervalo de corte. No Experimento 2, sete características foram modificadas pela condição de adubação e nenhuma foi influenciada pela interação entre o intervalo de corte e a condição de adubação (Tabela 2).

No Experimento 1, não houve ocorrência de perfilhos reprodutivos e o número de perfilhos vegetativos não foi influenciado pelo intervalo de corte, apresentando valor médio de 895 perfilhos 
$\mathrm{m}^{-2}$. Já no Experimento 2, os números de perfilhos vegetativos e reprodutivos foram influenciados pela adubação e o número de perfilhos reprodutivos também foi modificado pelo intervalo de corte.

Tabela 2. Coeficiente de variação e significância para os efeitos de intervalo de corte, condição de adubação e interação para as variáveis respostas avaliadas no capim-marandu durante o Experimento 1 e o Experimento 2

\begin{tabular}{|c|c|c|c|c|c|c|}
\hline \multirow{2}{*}{ Variável } & \multicolumn{2}{|c|}{ Experimento 1} & \multicolumn{4}{|c|}{ Experimento 2} \\
\hline & IC & CV (\%) & IC & $\mathbf{C A}$ & IC $\times$ CA & CV (\%) \\
\hline NPV & 0,0918 & 22,3 & $0,0306^{*}$ & $0,0018^{*}$ & 0,0891 & 18,6 \\
\hline NPR & - & - & 0,0771 & $0,0002^{*}$ & 0,1413 & 20,2 \\
\hline NFV & 0,1314 & 8,0 & 0,0967 & 0,2009 & 0,2009 & 10,9 \\
\hline $\mathrm{CC}$ & $0,0021^{*}$ & 7,9 & $0,0048^{*}$ & $0,0126^{*}$ & 0,0901 & 5,4 \\
\hline CLF & $0,0309^{*}$ & 11,2 & $0,0009^{*}$ & $0,0046^{*}$ & 0,7488 & 7,7 \\
\hline LLF & 0,1405 & 10,3 & 0,1522 & 0,1608 & 0,1393 & 9,0 \\
\hline EELF & $0,0081^{*}$ & 13,6 & $0,0387^{*}$ & $0,0401^{*}$ & 0,1002 & 12,0 \\
\hline AFP & $0,0001^{*}$ & 14,3 & $0,0201^{*}$ & $0,0086^{*}$ & 0,1571 & 11,4 \\
\hline PP & $0,0064^{*}$ & 16,1 & $0,0045^{*}$ & $0,0004^{*}$ & 0,1212 & 14,5 \\
\hline
\end{tabular}

- Significativo ( $\mathrm{P}<0,05)$; -: nào mensurado; IC: intervalo de corte; $\mathrm{CV}$ : cocficiente de variaçào; $\mathrm{CA}$ : condiçào de adubaçào; NPV: número de perfilho vegetativo/m²; NPVR: número de perfilho reprodutivo/m²; NFV: número de folha viva/perfilho; $\mathrm{CC}$ : comprimento do colmo; CLF: comprimento da lâmina foliar; LLF: largura da lâmina foliar; EELF: espaço entre lâmina foliar; AFP: área foliar por perfilho; PP: peso do perfilho.

O capim-marandu submetido à dose de adubo mais alta apresentou maior número de perfilhos vegetativos e reprodutivos, em comparação àquele sob baixa dose de adubo (Figura 1A). No segundo ano experimental, as maiores densidades populacionais de perfilhos reprodutivos foram encontradas quando o intervalo de corte foi maior, sendo nula nos dois intervalos menores (Figura 1B).

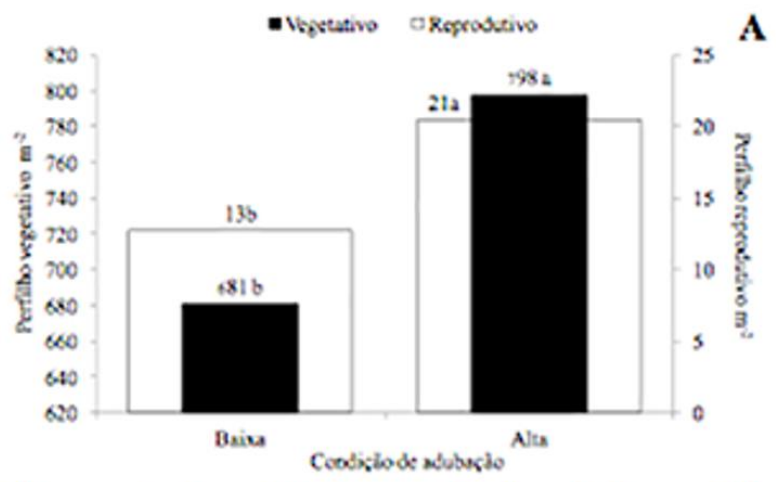

$\mathbf{A}$

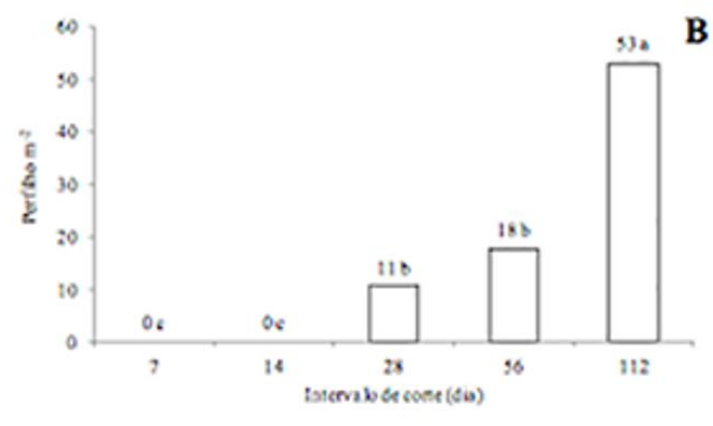

Figura 1. Densidade populacional de perfilhos vegetativos e reprodutivos sob condições de adubação (A) e número de perfilho reprodutivo em dosséis de capim-marandu manejado com intervalos de corte (B) no segundo ano experimental. Para cada característica, médias seguidas de letras diferentes diferem pelo teste de Tukey $(\mathrm{P}<0,05)$. Baixa: $75 \mathrm{~kg} \mathrm{ha}^{-1} \mathrm{de} \mathrm{N}$; Alta: $300 \mathrm{~kg} \mathrm{ha}^{-1}$ de $\mathrm{N}$. 
O número de folhas vivas por perfilho não variou entre os intervalos de corte e as condições de adubação e apresentou valores de 4,8 e 3,6 no Experimento 1 e 2, respectivamente. Em ambos os anos experimentais, a redução do intervalo de corte ocasionou diminuição do comprimento do colmo (Figura 2A). Quanto à condição de adubação, no Experimento 2 observou-se que o capimmarandu sob alta dose de adubo obteve maior comprimento de colmo do que quando adubado com dose menor (Figura 2B).
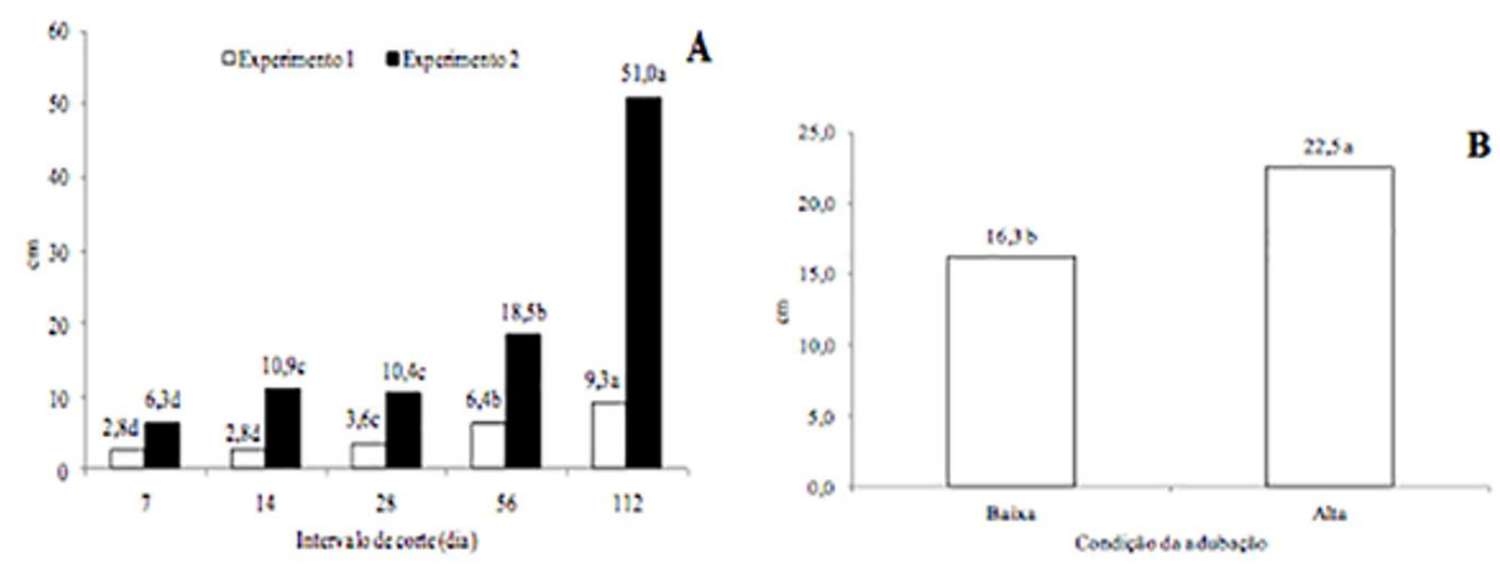

Figura 2. Comprimento do colmo em perfilho de capim-marandu submetido à intervalos de corte (A) e condições de adubação (B). No gráfico A, em cada experimento, e no gráfico B, as médias seguidas de letras diferentes diferem pelo teste de Tukey $(\mathrm{P}<0,05)$. Baixa: $75 \mathrm{~kg}$ ha-1 de N; Alta: $300 \mathrm{~kg} \mathrm{ha}^{-1}$ de N.

No primeiro experimento, o comprimento da lâmina foliar foi maior que os demais quando a planta foi submetida ao maior intervalo de corte. De modo semelhante, no Experimento 2, em geral, a redução do intervalo de corte resultou em menores tamanhos de folha (Figura 3A). Em relação à condição de adubação, no Experimento 2 foi constatado que o capim-marandu sob alta dose de adubo apresentou folhas mais compridas, comparado às menores doses (Figura 3B).

A largura da lâmina foliar não variou entre os intervalos de corte e as condições de adubação, e apresentou valores de 1,3 e 1,5 cm no Experimento 1 e 2, respectivamente.
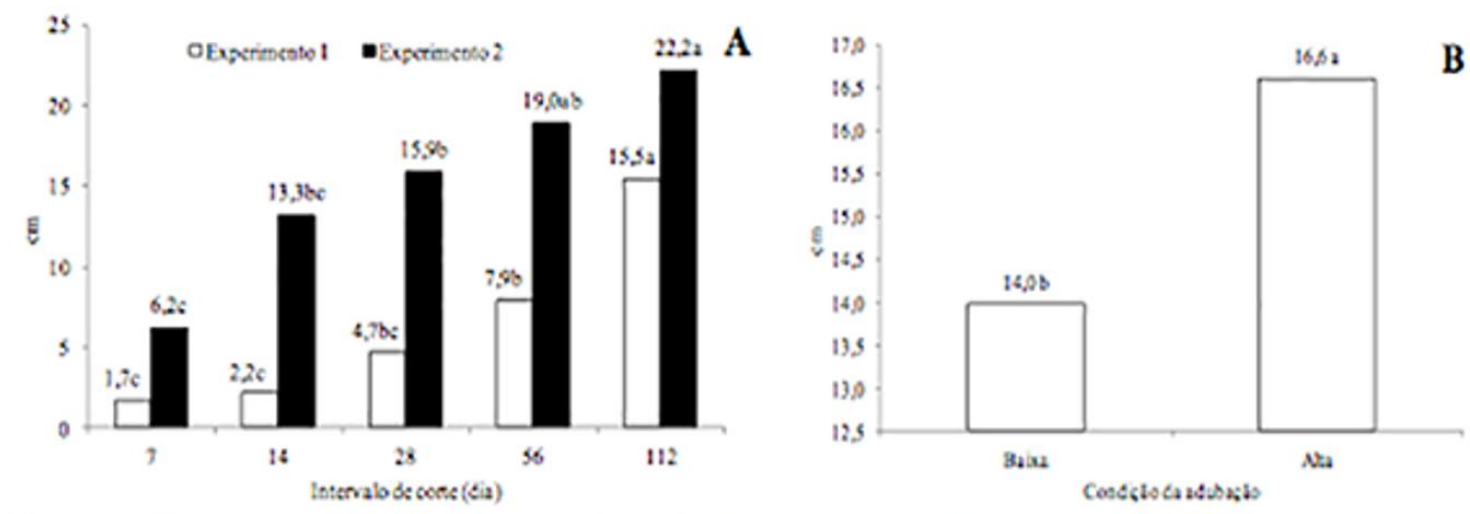

Figura 3. Comprimento da lâmina foliar em perfilho de capim-marandu submetido à intervalos de corte (A) e condições de adubação (B). No gráfico A, em cada experimento, e no gráfico $B$, as médias seguidas de letras diferentes diferem pelo teste de Tukey $(\mathrm{P}<0,05)$. Baixa: $75 \mathrm{~kg} \mathrm{ha}^{-1}$ de N; Alta: $300 \mathrm{~kg} \mathrm{ha}^{-1}$ de N. 
Quanto ao espaço entre as lâminas foliares no perfilho, o mesmo padrão de resposta foi obtido para os dois experimentos, isto é, o dossel cortado com 112 dias de rebrotação apresentou maior espaço entre as lâminas foliares do que os demais (Figura 4A). Quando a maior dose de adubos foi utilizada, no Experimento 2, o espaço entre as lâminas foliares também aumentou, em comparação ao uso de menor dose de adubo (Figura 4B).
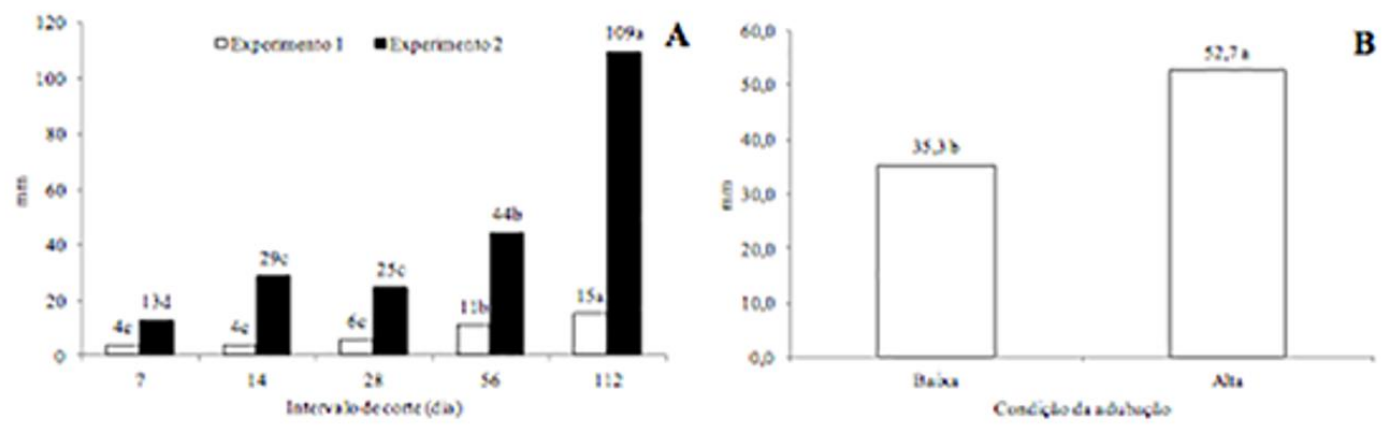

Figura 4. Espaço entre lâminas foliares em perfilho de capim-marandu submetido à intervalos de corte (A) e condições de adubação (B). No gráfico A, em cada experimento, e no gráfico $B$, as médias seguidas de letras diferentes diferem pelo teste de Tukey $(P<0,05)$. Baixa: $75 \mathrm{~kg} \mathrm{ha}^{-1}$ de N; Alta: $300 \mathrm{~kg} \mathrm{ha}^{-1}$ de N.

Referente ao Experimento 1, a área foliar do perfilho foi maior com o intervalo de corte de 112 dias em relação aos demais avaliados. O mesmo ocorreu no Experimento 2; entretanto, com o menor intervalo de corte $(7$ dias), a área foliar do perfilho foi menor em comparação àqueles submetidos ao corte a cada 28 e 56 dias (Figura 5A). A maior condição de adubação realizada no Experimento 2 proporcionou maior área foliar do perfilho do capim-marandu, quando comparada ao uso de uma quantia baixa de adubos (Figura 5B).
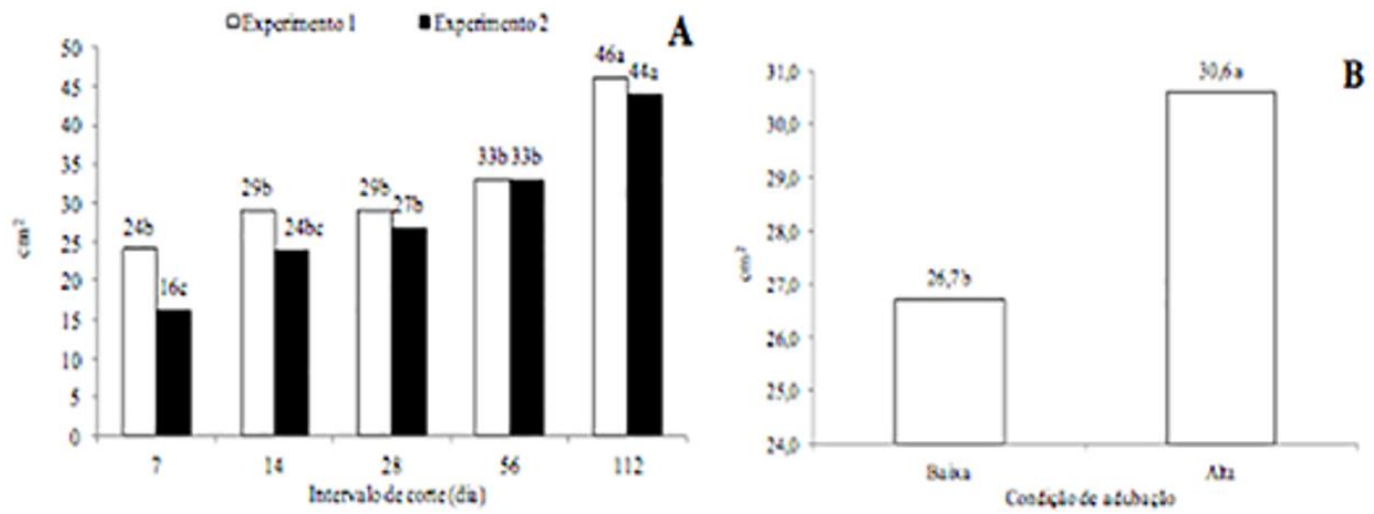

Figura 5. Área foliar do perfilho de capim-marandu submetido à intervalos de corte (A) e condições de adubação (B). No gráfico $\mathrm{A}$, em cada experimento, e no gráfico $\mathrm{B}$, as médias seguidas de letras diferentes diferem pelo teste de Tukey $(\mathrm{P}<0,05)$. Baixa: $75 \mathrm{~kg} \mathrm{ha}^{-1} \mathrm{de} \mathrm{N}$; Alta: $300 \mathrm{~kg} \mathrm{ha}^{-1}$ de $\mathrm{N}$.

As respostas do peso do perfilho do capim-marandu foram crescentes com o intervalo de corte, em ambos os experimentos (Figura 6A). No Experimento 2, a maior dose de adubos foi responsável 
pelo maior peso do perfilho do capim-marandu, em comparação à dose baixa (Figura 6B).

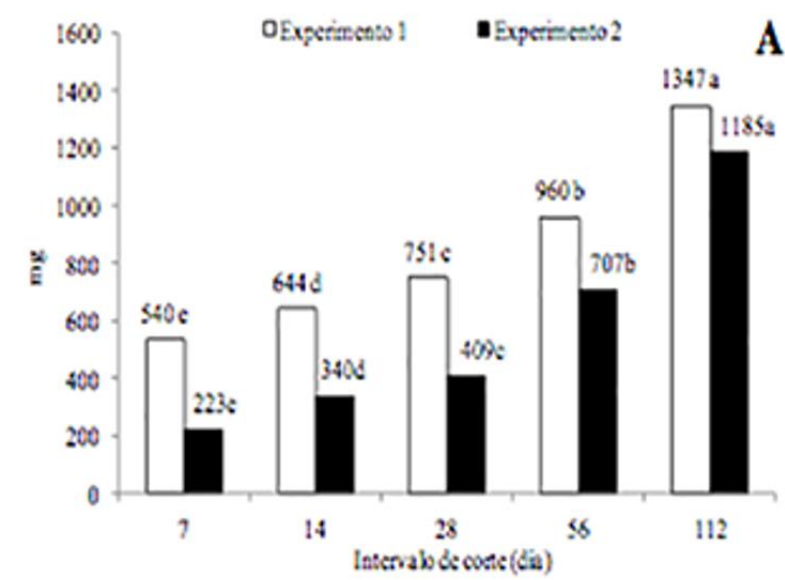

A

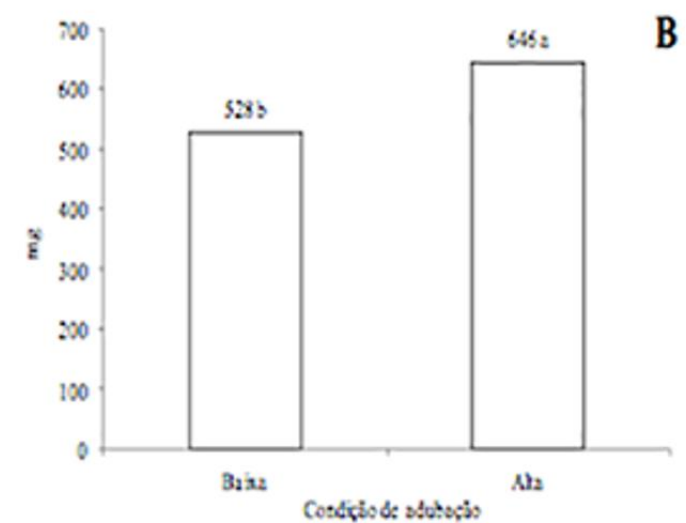

Figura 6. Peso do perfilho de capim-marandu submetido à intervalos de corte (A) e condições de adubação (B). No gráfico $\mathrm{A}$, em cada experimento, e no gráfico $\mathrm{B}$, as médias seguidas de letras diferentes diferem pelo teste de Tukey $(\mathrm{P}<0,05)$. Baixa: $75 \mathrm{~kg} \mathrm{ha}^{-1} \mathrm{de} \mathrm{N}$; Alta: $300 \mathrm{~kg} \mathrm{ha}^{-1}$ de $\mathrm{N}$.

\section{Discussão}

A condição experimental vigente no Experimento 1, caracterizada por baixas altura de corte $(5 \mathrm{~cm})$ e nível de adubação (70 $\mathrm{kg} \mathrm{ha}^{-1}$ de $\mathrm{N}$ e $21,5 \mathrm{~kg} \mathrm{ha}^{-1} \mathrm{de} \mathrm{P}$ ), pode ser considerada muito severa, razão pela qual, no Experimento 2, a altura de corte foi aumentada para $10 \mathrm{~cm}$. Nesse contexto, em condições de campo, caso seja adotada reduzida altura de corte, recomenda-se a adoção de maior intervalo de corte e, ou maior nível de adubação.

Os perfilhos reprodutivos não foram encontrados no Experimento 1 devido, provavelmente, à época do florescimento do capim-marandu, que é concentrada a partir de março, no outono ${ }^{(11)}$, mês em que o fotoperíodo se encurta, promovendo o florescimento da planta. Como no Ano 1 o experimento terminou em fevereiro, a planta não emitiu as inflorescências. Isso não ocorreu no Experimento 2, que apresentou tais perfilhos pois o trabalho em campo terminou no mês de março. A ausência de perfilhos reprodutivos no Experimento 1 também pode ter sido resultado da menor altura de corte $(5 \mathrm{~cm})$ adotada neste experimento. Com esse manejo, é possível que muitos perfilhos tenham tido o seu meristema apical eliminado, quando iniciaram a transição do estádio vegetativo pra o reprodutivo, o que impediu a ocorrência desta última classe de perfilho no dossel forrageiro. Por outro lado, o aumento do intervalo de corte propiciou a emissão dos perfilhos reprodutivos, porque a planta não teve seu crescimento interrompido e completou seu desenvolvimento fenológico (Figura 1B).

A adubação nitrogenada interfere na morfogênese da planta forrageira de várias maneiras. $\mathrm{O}$ nitrogênio $(\mathrm{N})$ aumenta a taxa de aparecimento foliar ${ }^{(12)}$ e, com efeito, o número de gemas aptas para se desenvolver em perfilhos, o que pode justificar, no segundo experimento, o aumento do número de perfilhos vegetativos e reprodutivos com a adubação nitrogenada (Figura 1A). Morais et 
al. ${ }^{(13)}$ avaliaram o perfilhamento da $B$. decumbens cv. Basilisk adubada com 75, 150, 225 e 300 $\mathrm{kg} \cdot \mathrm{ha}^{-1}$ de $\mathrm{N}$ e a última dose resultou em maior número de perfilho no pasto.

A adubação nitrogenada aumenta a eficiência fotossintética e atua nas zonas meristemáticas da folha, estimulando o alongamento de colmo e a taxa de alongamento foliar ${ }^{(14,15)}$, o que provavelmente ocorreu no Experimento 2, justificando os maiores comprimentos de colmo e de lâmina foliar nos perfilhos de capim-marandu com a maior dose do fertilizante (Figuras 2B e 3B).

O comprimento do colmo também foi maior quando o intervalo de corte aumentou (Figura 2A), porque a planta permaneceu por mais tempo em livre crescimento. Outro fator que pode explicar o maior comprimento do colmo com o maior intervalo de desfolhação é que a planta mais velha precisa sustentar seu maior peso para evitar o acamamento e o colmo é a estrutura de sustentação da planta forrageira ${ }^{(7)}$. Ademais, quando a planta fica mais alta, há maior competição intraespecífica por luz entre os perfilhos, o que faz com que o colmo se alongue. Segundo Carnevalli et al. ${ }^{(16)}$, durante a rebrotação do pasto, quando o dossel passa a interceptar 95\% da luz incidente (índice de área foliar crítico), os perfilhos competem por luz e, como estratégia, ocorre o alongamento do colmo para expor as folhas em um estrato mais alto do dossel. Como o colmo possui menor teor protéico e maior percentagem de fibra indigestível em comparação à folha viva ${ }^{(17)}$ e também é rejeitado pelo animal em pastejo ${ }^{(18)}$, não seria recomendado o descanso do pasto por períodos longos (56 ou 112 dias) durante a época das águas. Sob essas condições, a quantidade de colmo ofertada seria grande, contrariamente ao observado quando se trabalha com intervalos de corte menores (28 dias). Nesse sentido, a redução do intervalo de corte é estratégia eficiente para se controlar o alongamento o colmo do capim-marandu, principalmente em pastos adubados, que expressam maior taxa de crescimento ${ }^{(19)}$.

O comprimento da lâmina foliar também aumentou com o maior intervalo de corte, em ambos os experimentos (Figura 3A). Para que as folhas sejam expostas, elas devem percorrer um trajeto, desde o meristema apical, localizado no interior do pseudocolmo, até a ponta do perfilho. Quando o tempo de corte é maior, o tamanho do pseudocolmo aumenta e a distância que as novas folhas percorrem para serem expostas é maior. Com isso, a folha jovem fica se alongando por maior período, resultando em maior comprimento de sua lâmina foliar ${ }^{(20)}$. O contrário ocorreu com o menor intervalo de corte, em que o colmo ficou mais curto e o percurso que a folha nova teve que percorrer para a exposição no ápice do perfilho foi menor, resultando em folhas mais curtas.

Com o alongamento do colmo causado pela adubação (Figura 2B) e a estabilidade do número de folha por perfilho ${ }^{(21)}$, o espaço entre a inserção de duas folhas consecutivas no colmo também aumentou com a adubação (Figura 4B). Por outro lado, o menor intervalo de corte resultou em colmo mais curto e, assim, as folhas ficaram mais próximas (Figura 4A). A redução do intervalo de corte também resultou em lâminas foliares mais curtas (Figura 3A). Esses resultados demonstram a capacidade do capim-marandu de se adaptar à desfolhação, alterando sua morfologia para manter seus órgãos fotossintéticos íntegros ${ }^{(22)}$. Dessa forma, ao invés de a planta reduzir a quantidade de folhas por ter colmo mais curto, ela mantém a mesma quantidade de folhas, porém estas ficam mais próximas umas das outras. Essa resposta morfológica pode otimizar o aproveitamento da luz pelo dossel forrageiro e, com efeito, contribuir para a persistência da planta em condições de desfolhações mais severas.

A distância entre as lâminas foliares foi menor no Experimento 1 do que no Experimento 2 (Figura $4 \mathrm{~A}$ ), provavelmente porque no primeiro experimento a altura de corte foi demasiadamente baixa ( 5 $\mathrm{cm}$ ), o que pode ter reduzido o alongamento dos entrenós do perfilho e, consequentemente, 
diminuído a distância entre as lâminas foliares. A menor precipitação pluvial no Experimento 1 em relação ao Experimento 2 (Tabela 1) também pode ter contribuído para esse resultado.

Altas doses de nitrogênio $(\mathrm{N})$ promovem o crescimento da planta e, consequentemente, a expansão do comprimento da folha ${ }^{(23)}$, o que foi comprovado neste experimento. Dessa forma, com lâminas foliares maiores, tem-se também maior área foliar do perfilho (Figura 5B). Esta variável também aumenta com o maior intervalo de corte, pois é natural que folhas com maior tamanho resultem em uma área foliar do perfilho maior (Figura 5A). A maior área foliar do perfilho somada aos seus colmos mais longos também resultou em perfilhos maiores e mais pesados na presença de $\mathrm{N}$.

O colmo é o componente mais pesado da planta forrageira e por ter se mostrado mais comprido na presença de mais nitrogênio e fósforo no solo, é natural que o peso do perfilho seja superior. Além disso, a maior quantidade de nitrogênio e de fósforo no solo interfere nas respostas morfofisiológicas da planta forrageira, como atividade fotossintética, mobilização de reservas após a desfolhação e taxa de expansão da área foliar ${ }^{(12)}$. Assim, a aplicação da maior dose de nitrogênio e de fósforo resultou em maior peso do perfilho (Figura 6B). Naturalmente, com o aumento do intervalo de corte, os componentes morfológicos ficam mais velhos, maiores e mais pesados, o que causou maior peso do perfilho nos dois experimentos (Figura 6A). Nesse sentido, Santos et al. ${ }^{(24)}$, em estudo de correlação entre o peso do perfilho e o comprimento do colmo da Urochloa decumbens cv. Basilisk, verificaram associação significativa $(\mathrm{P}<0,01)$ e positiva $(0,82)$ entre essas características. Esse resultado foi atribuído ao fato de os perfilhos mais pesados geralmente possuírem maior estádio de desenvolvimento e, por conseguinte, seus colmos atingem maiores comprimentos. Além disso, plantas sob sombreamento, situação comum nos dosséis com perfilhos mais pesados, também apresentam, como resposta morfológica, incremento do comprimento do colmo para favorecer a localização das folhas jovens e mais fotossinteticamente ativa da planta na região superior do dossel, onde a luminosidade é maior.

Os resultados deste trabalho demonstram que, em geral, a condição de adubação e o intervalo de desfolhação foram efetivos para alterar alterar a morfologia dos perfilhos do capim-marandu, não sendo possível discernir sobre a maior importância de um fator em comparação ao outro. De fato, no Ano 2, 67\% das variáveis respostas foram influenciadas pelo intervalo de corte e $78 \%$ pela condição de adubação (Tabela 2). Além disso, esses resultados indicam que os efeitos da adubação e da intensidade de desfolhação são de natureza contrária. Essa compensação de efeitos pode justificar, em parte, o fato de o pasto sob alta dose de adubado se adaptar melhor à maior severidade de desfolhação.

\section{Conclusões}

O capim-marandu adapta sua morfologia em resposta à desfolhação e à adubação. Exceto para a densidade populacional de perfilhos, as demais modificações morfológicas nos perfilhos do capimmarandu causadas pela desfolhação e pela adubação são de natureza contrária. Enquanto a maior dose de adubo aumenta o tamanho dos órgãos, o espaço entre lâminas foliares, a área foliar e o peso de perfilho, a severidade de desfolhação tem efeitos contrários. 


\section{Referências}

1. Soares Filho CV. Recomendações de espécies e variedades de brachiarias para diferentes condições In: Simpósio sobre manejo de pastagem - brachiaria, 11., Piracicaba - SP, 1994. Anais. Piracicaba: FEALQ, 1994, P. 25-29.

2. Ghisi OMA, Pedreira JVS. Características agronômicas das principais Brachiaria spp. In: Pedreira JVS, Meirelles NMF. Encontro sobre capins do gênero Brachiaria, Nova Odessa, 1986. Anais. Nova Odessa, SP: Instituto de Zootecnia, 1987. p. 19-58.

3. Paula CCL, Euclides VPB, Lempp B, Barbosa RA, Montagner DB, Carloto MN. Acúmulo de forragem, características morfogênicas e estruturais do capim-marandu sob alturas de pastejo. Ciência Rural. 2012. 42:2059-2065. Available from: http://www.scielo.br/pdf/cr/2012nahead/a30412cr5188.pdf. Portuguese.

4. Santos MER, Fonseca DM, Gomes VM, Santos AL, Castro MRS, Albino RL. Diversidade de perfilhos em pasto de Brachiaria decumbens manejado sob lotação contínua. Boletim de Indústria Animal (Impresso). $2011 ; 68: 17-26$.

5. Santos MER, Aquino R, Romao MC. Morfologia de fitômeros de capim-elefante. Revista Brasileira de Agropecuária Sustentável. 2011. 1:104-111. Available from:

http://www.rbas.com.br/index.php/rbas/article/viewFile/20/18. Portuguese.

6. Santos MER, Fonseca DMF, Gomes VM, Castro, MRS, Carvalho, VV. Desfolhação de perfilhos em pasto de capim-braquiária sob lotação contínua. Ciência Animal Brasileira. 2011 Apr/May;12(2):241-249.

Available from: http://www.revistas.ufg.br/index.php/vet/article/view/7541/9227. Portuguese.

7. Sousa BML, Vilela HH, Santos ME R, Rodrigues CS, Santos, AL, Nascimento Junior D, Assis CZ, Rocha GO. Characterization of tillers in deferred Piata palisade grass with different initial heights and nitrogen levels. Revista Brasileira de Zootecnia. 2012. 41(7): 1618-1624. Avaible from:

http://www.scielo.br/pdf/rbz/v41n7/09.pdf. English.

8. Silva CCF, Bonomo P, Pires AJV, Maranhão CMA, Patês NMS, Santos LC. Características morfogênicas e estruturais de duas espécies de braquiária adubadas com diferentes doses de nitrogênio. Revista Brasileira de Zootecnia. 2009. 38(4):657-661. Avaible from:

http://www.revista.sbz.org.br/artigo/visualizar.php?artigo=6389. Portuguese.

9. EMPRESA BRASILEIRA DE PESQUISA AGROPECUÁRIA - EMBRAPA. Centro Nacional de Pesquisa de Solos. Sistema brasileiro de classificação de solos. Rio de Janeiro: EMBRAPA. 2006. 306p.

10. Cantarutti R B, Martins CE, Carvalho MM, Fonseca DM, Arruda ML, Vilela H, Oliveira FTT.

Pastagens. In: Ribeiro AC, Guimarães PTG, Alvarez VVH. Comissão de Fertilidade do Solo do Estado de Minas Gerais. Recomendação para o uso de corretivos e fertilizantes em Minas Gerais. Viçosa - $5^{\text {a }}$ Aproximação. 1999. p. 332 - 341.

11. Paula CCL, Euclides VPB, Lempp B, Barbosa RA, Montagner DB, Carloto MN. Acúmulo de forragem, características morfogênicas e estruturais do capim-marandu sob alturas de pastejo. Ciência Rural. 2012 Nov; 42(11): 2059-2065. Available from: http://www.scielo.br/scielo.php\%3Fpid=S0103-

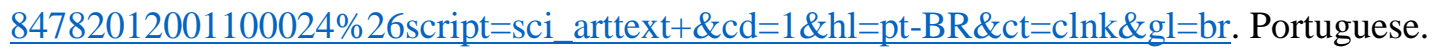

12. Martuscello JA, Fonseca DM, Nascimento Junior D. Características morfogênicas e estruturais do capimxaraés submetido à adubação nitrogenada e desfolhação. Revista Brasileira de Zootecnia. 2005. 34(5):14751482. Avaible from: http://www.scielo.br/pdf/rbz/v34n5/26627.pdf. Portuguese.

13. Morais RV, Fonseca DM, Nascimento Junior D, Ribeiro Junior JI, Fagundes JL, Moreira LM, Mistura C, Martuscello JA. Demografia de perfilhos basilares em pastagem de Brachiaria decumbens adubada com N. Revista Brasileira de Zootecnia. 2006. (35)2:380-388. Available from: http://www.scielo.br/pdf/rbz/v35n2/a07v35n2.pdf. Portuguese. 
14. Bélanger G. Morphogenetic characteristics of Timothy grown with varying N nutrition. Canadian Journal of Plant Science. 1998 Jan;78(1):103-108. Available from; http://pubs.aic.ca/doi/abs/10.4141/P97-015. English.

15. Garcez Neto AF, Nascimento Júnior D, Regazzi O, Fonseca DM, Mosquim DR, Gobbi KF. Respostas morfogênicas e estruturais de Panicum maximum cv. Mombaça sob diferentes níveis de adubação nitrogenada e alturas de corte. Revista Brasileira de Zootecnia. 2002: 31(5):1890-1900. Available from: http://www.scielo.br/pdf/rbz/v31n5/a04v31n5.pdf. Portuguese.

16. Carnevalli RA, Da Silva SC, Bueno AAO, Uebele MC, Bueno FO, Hodgson J, Silva GN, Morais JPG. Herbage production and grazing losses in Panicum maximum cv. Mombaça under four grazing managements. Tropical Grasslands. 2006. 40:165-176.

http://tropicalgrasslands.info/public/journals/4/Historic/Tropical\%20Grasslands\%20Journal\%20archive/PDF s/Vol_40_2006/Vol_40_03_2006_pp165_176.pdf. Available from: Portuguese.

17. Silva SHB, Santos MVF, Lira MA, Dubeux Júnior JCB, Freitas EV, Ferreira, RLC. Uso de descritores morfológicos e herdabilidade de caracteres em genótipos de capim-elefante de porte baixo. Revista Brasileira de Zootecnia. 2009:38(8):1451-1459. Available from: http://www.scielo.br/scielo.php?pid=S151635982009000800008\&script=sci_arttext. Portuguese.

18. Santos MER, Gomes VM, Fonseca, DM. Fatores causadores de variabilidade espacial do pasto de capim braquiária: manejo do pasto, estação do ano e topografia do terreno. Bioscience Journal. 2014 Jan;30(1):210218. Available from: http://www.seer.ufu.br/index.php/biosciencejournal/article/viewFile/18020/13702. Portuguese.

19. Santos MER, Barbero LM, Nascimento Junior D, Fonseca DM. Manejo do pastejo em sistemas de alto nível tecnológico. Belo Horizonte - Informe Agropecuário. 2012. 33, p. 7-14.

20. Santos MER, Fonseca DM, Braz TGS, Silva SP, Gomes VM, Silva GP. Características morfogênicas e estruturais de perfilhos em locais do pasto de capim-braquiária com alturas variáveis. Revista Brasileira de Zootecnia. 2011. 40:535-542. Available from: http://www.scielo.br/pdf/rbz/v40n3/10.pdf. Portuguese.

21. Lemaire G, Chapman D. Tissue flows in grazed plant communities. In: Hodgson J, Illius AW, editors. The ecology and management of grazing systems. Wallingford: CAB International; 1996. P.3-36. English.

22. Valladares F, Gianoli E, Gómez JM. Ecological limits to plant phenotypic plasticity. New Phytologist. 2007 Nov; 176 (4): 749-763. Available from: http://onlinelibrary.wiley.com/doi/10.1111/j.14698137.2007.02275.x/full. English.

23. Oliveira AB, Pires AJV, Matos Neto U, Carvalho GGP, Veloso CM, Silva FF. Morfogênese do capimtanzânia submetido a adubações e intensidades de corte. Revista Brasileira de Zootecnia. 2007 Jul;34(4) suplemento:1006-1013. Available from: http://www.scielo.br/scielo.php?script=sci_arttext\&pid=S151635982007000500004. Portuguese.

24. Santos MER, Fonseca DM, Gomes VM, Silva SP, Santos AL. Correlações entre características estruturais do capim-braquiária sob três intensidades de pastejo. Enciclopédia Biosfera.2010. 6:1-9. Available from: http://www.conhecer.org.br/enciclop/2010/correlacoes.pdf. Portuguese. 